Despite recent concerns about weapons of mass destruction, explosions are by far the most common cause of disasters associated with terrorism. Of 93 reported terrorist acts producing 30 or more casualties from 1991-2000, 82 $(88 \%)$ involved explosions. These attacks not only resulted in significant death and destruction, but also challenged emergency medical systems in 27 countries. ${ }^{1}$ The largest of these bombings were catastrophic medical disasters, generating hundreds to thousands of casualties, acutely overwhelming local prehospital and emergency department resources. ${ }^{2}$

Emergency physicians play a pivotal role in the immediate medical response to terrorist bombing events. They not only triage, treat, and determine the disposition of immediately surviving injured victims, they also provide prehospital medical control, manage emergency department resources, solve logistical problems, and calm a terrified public. Accordingly, they must understand the mechanisms, types, frequency, severity, and time course of injuries in terrorist bombings, as well as be familiar with the many lessons learned from past responses to terrorist bombing events.

This presentation reviewed the epidemiology of multiple and mass-casualty terrorist bombings, and discusses the implications for emergency department response. Although it is prudent to "expect the unexpected", a rational approach to disaster management incorporates what already is known into the basis for planning and preparedness. As long as terrorists continue to use explosions to achieve their goals, terrorist bombings must remain a focus of medical disaster preparedness.

References:

1. Terror Attack Database. International Policy Institute for CounterTerrorism Web Site. Available at: http://www.ict.org.i1/. Accessed 22 January, 2002.

2. Mahoney LE, Reutershan TP. Catastrophic disasters and the design of disaster medical care systems. Ann Emerg Med 1987;16(9):227-233.

Keywords: bombings; emergency departments; emergency management; emergency medicine; epidemiology; explosives; planning; preparedness; response; terrorism

Prebosp Disast Med 2002;17:s13-14.

\section{World Trade Center Tragedy; An Economic Analysis Using YPLL (Years of Potential Life Lost) Zafar Abmed; ${ }^{1}$ Azhar Abdul Aziz ${ }^{2}$ \\ 1. National University Hospital and Lt, Malaysia \\ 2. National University of Malaysia}

Objective: To analyze the economic loss because of life lost as a result of attack at World Trades Center (WTC) because of terrorist attack on 11 September 2001.

Methodology: The list of people who lost their life as a result of attack on the WTC on 11 September 2001 was analyzed. From this list, the number of the productive life years these victims have lost will be deduced using the age at the time of death from the average age in USA. This number of years lost will put into the YPLL equation to find the loss their families have suffered because of their early demise. Then, the individual life lost and their economic value will be added to determine the total economic loss incurred on the US economy as a result of the attack on the WTC.

Result : The economic impact as a result of life lost on the overall US economy because of that attack on the WTC on September 2001 will be analyzed.

Keywords: economic analysis; terrorism, World Trade Center, Yearsof-Potential-Life-Lost

Prehosp Disast Med 2002;17:s14.

\section{Forced Displacement: A Disaster in Colombia-The Case of Antioquia! \\ Emilio Huertas Arias}

Air Health Program-Antioquia's Section of Health, Columbia

Introduction: Forced displacement is the most important disaster in Colombia. The Non-Governmental Organisation, Counsellor for the Human Rights and the Forced Displacement (CODHES) registered 91,166 persons displaced during the first trimester of the year 2001. This is 34,210 more persons than during the previous year. Objective: To approach the problem of forced displacement in Antioquia.

Method: The Committee for the Integral Attention of Forced Displacement was established to address issues regarding the cause-effect pattern of the displacement relationships and the mechanisms designed to confront the problem, the structure and dynamics of the departmental and local committees, the system of information, training strategies, sensitization, and management.

Results: The process that was generated from the assessment of this disaster has generated a plan for mobilization of great magnitude that has been able to utilize important institutional and social resources to approach the phenomenon. As a result, we have assumed a no-violence attitude towards life.

Conclusion: Attention to the forced displacement in Antiguia has resulted in a non-violent approach that has had positive effects.

Keywords: attitude; Columbia; forced displacement; management; non-violence; sentization; strategies

Prebosp Disast Med 2002;17:s14.

\section{Survey and Cost-Analysis of Injuries in the Ji Ji Earthquake in Taiwan \\ Wen-Ta Chiu}

Institute of Injury Prevention and Control, Taipei Medical University, Taiwan

Objectives: On 21 September, 1999 at 01:47 hours, the Ji Ji Earthquake (Richter Scale of 7.3) struck Central Taiwan near the Nantou area, and caused great loss of life and economy. This paper focuses on the epidemiological survey of the Ji Ji Earthquake to provide data for future epidemiological studies with the goal of preventing disasters globally.

Methods: Information about the Ji Ji Earthquake was obtained from the courses provided by the government and from the Internet. Data of the deaths, injuries, and causes of death were supplied by Department of Health. The 